\title{
Acid Mediated Ring Closing Metathesis: A Powerful Synthetic Tool Enabling the Synthesis of Clinical Stage Kinase Inhibitors
}

\author{
Anthony D. Williamª and Angeline C.-H. Lee
}

\begin{abstract}
The powerful olefin metathesis reaction was employed for the construction of late-phase clinical agents SB1317 and SB1518. In both cases RCM seems to proceed only in the presence of an acid and to predominantly furnish trans isomers. In case of SB1518 it proceeded in the presence of acid $\mathrm{HCl}$, while for SB1317, it mainly proceeds in the presence of TFA (trifluroacetic acid).
\end{abstract}
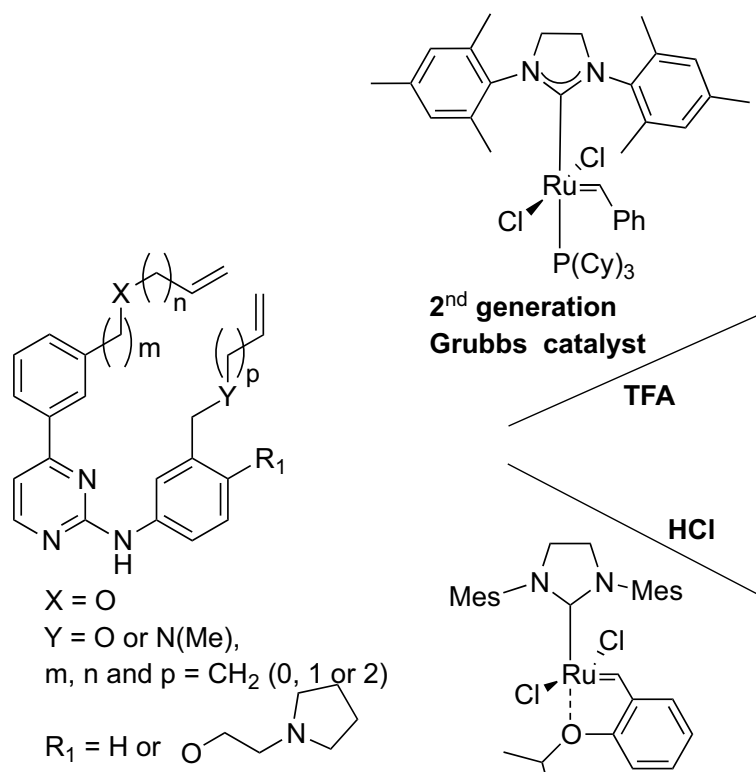

$2^{\text {nd }}$ generation Grubbs catalyst TFA<smiles>CC(C)Oc1ccccc1C=[R](Cl)(Cl)[C@H]1N(C)CCN1S(C)(=O)=O</smiles>

Hoveyda-Grubbs Catalyst<smiles></smiles>

95:5 (trans: cis)

SB1317

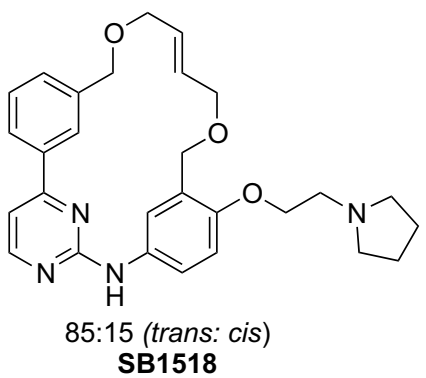

Keywords: Cyclin-dependent kinases (CDKs) · Grubbs catalyst · Janus kinase 2 (JAK2)

- Ring closing metathesis (RCM) $\cdot$ Zhan-1B catalyst

\section{Introduction}

The term macrocycle is usually associated with high molecular weight molecules

\footnotetext{
${ }^{*}$ Correspondence: Dr. A. D. William $\mathrm{S}$ BIO Pte Ltd

250 North Bridge Road

\#28-00 Raffles City Tower

Singapore 179101

Tel.: + 6567998526

E-mail: wanthony11@gmail.com

${ }^{a}$ Current Address: Institute of Chemical and Engineering Sciences (ICES)

Agency for Science, Technology, and Research

(A*STAR)

11 Biopolis Way, Helios Block, \#03-08

Singapore 138667, Singapore
}

that are primarily natural products. ${ }^{[1]}$ Due to their useful pharmacological properties many macrocycles have been developed into drugs. ${ }^{[2]}$ Despite their proven therapeutic potential macrocycles remain an under-explored chemical class in small molecule drug discovery probably due to their perceived structural complexity and poor drug-like properties. ${ }^{[3]}$ However, we envisioned that macrocycles could be an excellent source of innovative small molecules in the competitive arena of kinase inhibitor drug discovery.

In our quest for kinase inhibitors with an amino-pyrimidine ring system as the core-binding motif, we screened our in- house library with structures of type ' $A$ ' that demonstrated a broad kinase inhibitory activity in numerous cancer cell lines. However, the pyrimidine-based cores are heavily patented limiting the development of proprietary compounds. We envisioned that by fusing the open ends $R_{1}$ and $R_{2}$ to form macrocycles would access new intellectual property (Scheme 1).

Thus, using RCM as a synthetic tool we embarked on the synthesis of novel small molecule macrocycles. 


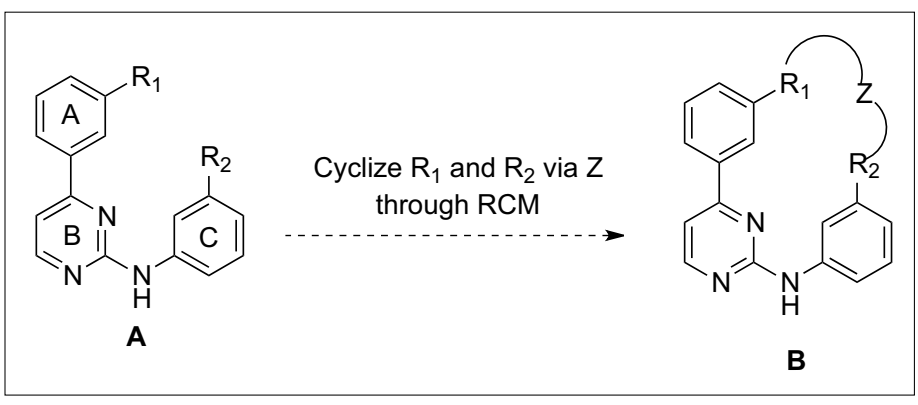

Scheme 1. Concept for small molecule macrocycles.

\section{Results and Discussions}

Small Molecule Macrocycle SB1317

Kinase inhibitors which inhibit more than one kinase have yielded better clinical results than selective compounds as they block more than one pathway critical for tumour growth. ${ }^{[4]}$ SB1317 not only inhibits key Cyclin-dependent kinases (CDKs) but other kinases such as Janus kinase 2 (JAK2) and Fms-like tyrosine kinase 3 (FLT-3) that are implicated in the pathogenesis of hematological malignancies. While most of the CDK, JAK2 and Flt3 inhibitors in clinical trials have open chain structures, ${ }^{[5]}$ SB1317 is unusual in being a macrocyclic compound exhibiting the above spectrum of activities combined in a single molecule. ${ }^{[6]}$

\section{Synthesis}

The synthesis (Scheme 2) was initiated from 2,4-dichloropyrimidine (1). Suzuki coupling with boronic acid 2a afforded the left-hand fragment, biaryl 3a in $80 \%$ yield. ${ }^{[7]}$ The right-hand half of SB1317 was constructed from 3-nitrobenzadehyde (4) and $N$-methyl allylamine (5) via reductive amination which proceeded smoothly affording allyl-benzylamine $\mathbf{6}$ in good yield. ${ }^{[8]}$ Aniline 7 was obtained in quantative yield under $\mathrm{SnCl}_{2}$ reduction conditions. .9] $^{[9]}$

Coupling of 3a with 7 was accomplished in the presence of $\mathrm{HCl}$ in $n$-butanol (Scheme 3). ${ }^{[10]}$ De-benzylation of 8 was attempted under various standard conditions but without much success. ${ }^{[1]}$ Finally, it was achieved in 50\% yield using TMSI under normal reported conditions. ${ }^{[12]}$ Alkylation of the resulting phenol with homoallyl bromide $\mathbf{1 0}$ proceeded efficiently in the presence of cesium carbonate to furnish RCM precursor diene 11.[13]

To circumvent low yields associated with the benzyl protecting group and to aid scale-up activities, an atom-efficient synthesis of 11, without the use of a protecting group, was attempted. Suzuki coupling of $\mathbf{1}$ with phenol $\mathbf{2 b}$ proceeded pleasingly well (Scheme 2) to furnish $\mathbf{3 b}$ in $88 \%$ yield. Alkylation of $\mathbf{3 b}$ with bromide $\mathbf{1 0}$ afforded $\mathbf{1 3}$ in good yield (Scheme 4). The coupling of the two halves $\mathbf{1 3}$ and $\mathbf{7}$ proceeded efficiently in the presence of $\mathrm{HCl}$ to afford $\mathbf{1 1}$ in a much improved overall yield.
RCM was attempted on $\mathbf{1 1}$ as described in Table 1. Grubbs $1^{\text {st }}$ and $2^{\text {nd }}$ generation catalysts failed to afford any product under normal conditions (Table 1, entries 1
Scheme 3. Synthesis of key intermediate for RCM. and 2). RCM is ineffective with molecules having basic centres as the catalyst probably co-ordinates with the basic nitrogens rendering it inactive. ${ }^{[14]}$ We reasoned that neutralisation of the basic centre could free the catalyst, hence an attempt to close the macrocycle was made with $\mathrm{HCl}$ as an additive. We were delighted to find that the desired product had formed with good trans:cis ratios albeit in low yield with the 1 st generation catalyst (entry 3). An improvement was quickly realised with the $2^{\text {nd }}$ generation catalyst affording a moderate yield (entry 4). However, with TFA as an additive the RCM proceeded most smoothly, full conversion occurred in just

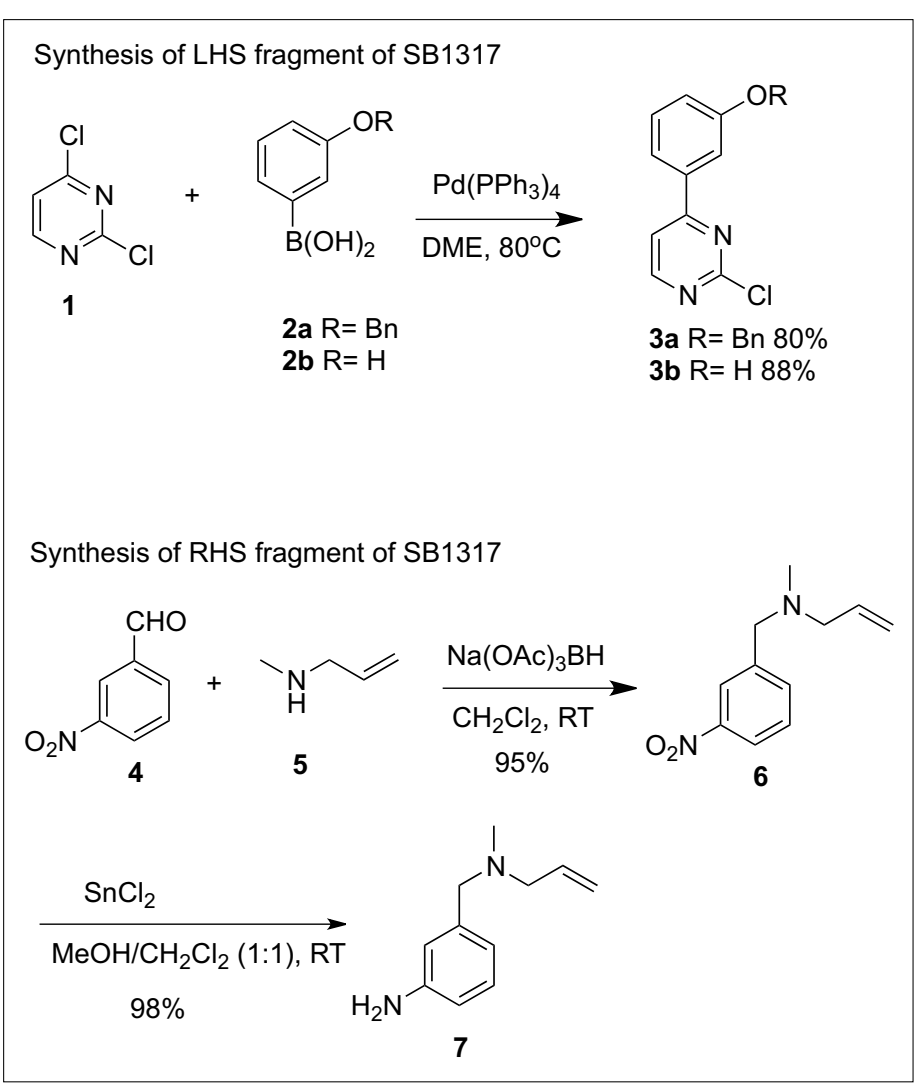

Scheme 2. Synthesis of key intermediates of SB1317.

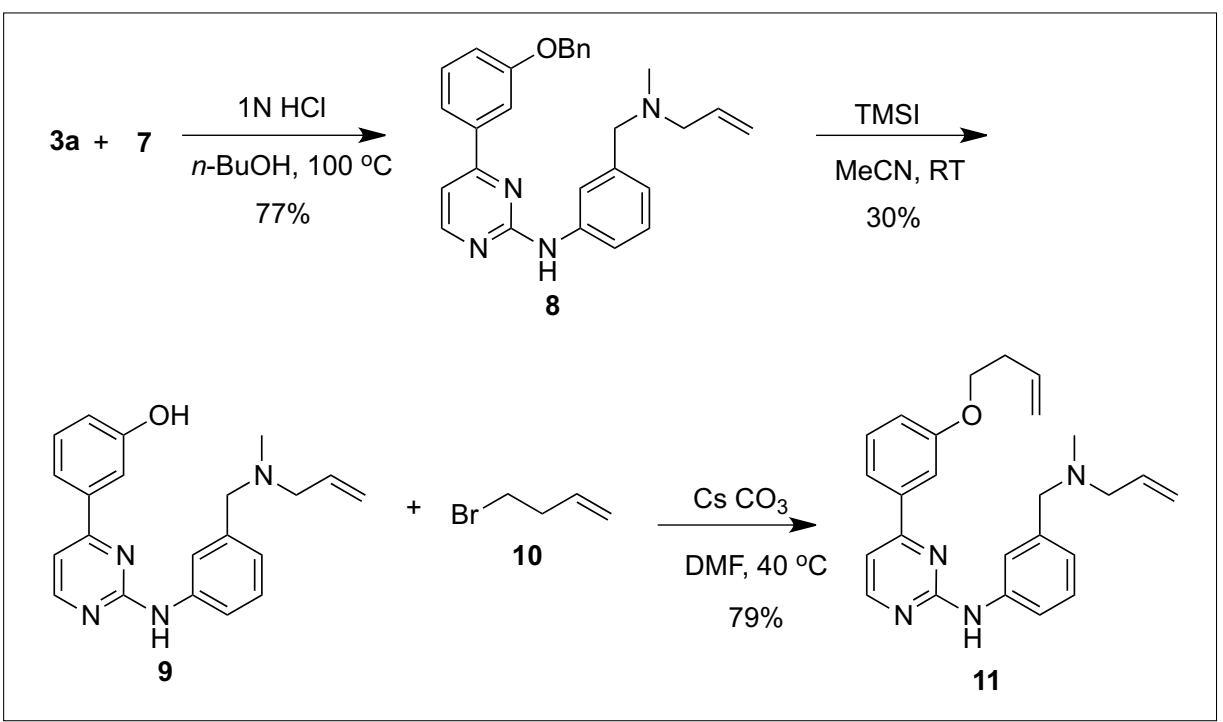




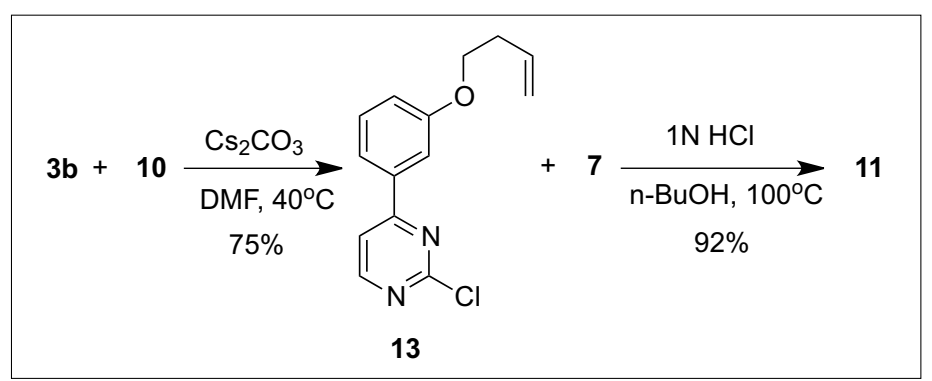

Scheme 4. Atom efficient synthesis of SB1317.
$4 \mathrm{~h}$ to furnish SB1317 in $86 \%$ yield with 94:6 trans: cis ratio on column chromatographic purification. The trans isomer purity was increased to $>98 \%$ by simply washing the solid with cold EtOAc with $90 \%$ recovery.

In conclusion, we have shown that RCM is a powerful synthetic tool for preparation of the novel small molecule macrocycle SB1317 which is otherwise very difficult to obtain by other means.

\section{Small Molecule Macrocycle SB1518}

Having completed phase 2 clinical trials and entered phase 3, SB1518 is a promising new therapeutic agent for myeloproliferative neoplasms (MPNs), particularly myelofibrosis (MF), and lymphoma. ${ }^{[15]}$ The synthesis of the precursor of SB1518 diene $\mathbf{1 4}$ is reported elsewhere. ${ }^{[15,16]}$ Herein in Table 2 the attempts of RCM with various catalysts are depicted.

Catalysis with Grubbs $1^{\text {st }}$ and $2^{\text {nd }}$ generation catalysts without additives under normal conditions did not proceed to completion, even after $36 \mathrm{~h}$. An attempt to close the macrocycle was made with $\mathrm{HCl}$ as an additive. It was encouraging to find that the desired product was formed albeit in low yield with the $1^{\text {st }}$ generation catalyst (entry 3 ). An improvement was quickly realized employing the $2^{\text {nd }}$ generation Grubbs catalyst. The reaction showed complete consumption of diene $\mathbf{1 4}$ in just $3 \mathrm{~h}$ to afford $60 \%$ of the product with trans:cis ratio 85:15 (entry 4). However, with HoveydaGrubbs $2^{\text {nd }}$ generation catalyst (entry 5) as well as Zhan-1B catalyst (entry 6) the RCM proceeded most smoothly. A high conversion with comparable trans: cis ratios was observed. SB1518 individual trans/cis isomers had similar biological activities towards JAK2 kinases and FLT3, hence all preclinical activities, including animal models, were performed with mixtures of tran/cis isomers. ${ }^{[15]}$

\section{Conclusion}

In conclusion, we have shown that RCM is a powerful synthetic tool for preparation of the novel small molecule macrocycles SB1518 and SB1317. Both have been prepared with atom efficient syntheses, devoid of protecting groups and
Table 1. Optimal Conditions for an Efficient RCM

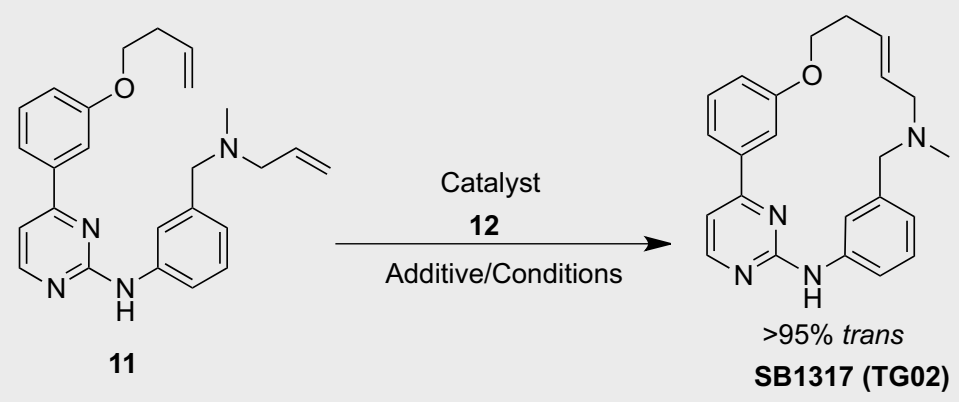

Entry Catalyst ${ }^{\mathrm{a}} \mathbf{( 1 2 )}$

1 Grubbs $1^{\text {st }}$ generation 16

2 Grubbs $2^{\text {nd }}$ generation $16 \mathrm{~h}$

3 Grubbs $1^{\text {st }}$ generation $\mathrm{HCl}, 16 \mathrm{~h} \quad 86: 14 \quad 10^{f}$

$\begin{array}{lllll}4 & \text { Grubbs } 2^{\text {nd }} \text { generation } & \mathrm{HCl}, 4 \mathrm{~h} & 94: 6^{e} & 70\end{array}$

5 Grubbs $1^{\text {st }}$ generation $\quad$ TFA, $16 \mathrm{~h} \quad 85: 15 \quad 8^{f}$

6 Grubbs $2^{\text {nd }}$ generation $\quad$ TFA, 4 h $\quad 94: 6^{e} \quad 86$

${ }^{\text {a} A l l ~ r e a c t i o n s ~ e m p l o y e d ~} 10 \mathrm{~mol} \%$ of Grubbs catalyst. ${ }^{\text {b }}$ Reactions were carried out in in $\mathrm{CH}_{2} \mathrm{Cl}_{2}$ in the presence of 5 equiv. of $4 \mathrm{M}$ methanolic $\mathrm{HCl}$ or TFA at reflux conditions. 'Determined by HPLC on crude sample. Isolated combined yields of cis and trans. ${ }^{\mathrm{e}}$ The trans isomer purity was increased to $>98 \%$ by simply washing the solid after column purification with cold EtOAc with $90 \%$ recovery. $\%$ of unreacted diene (11) was recovered. nd, not determined.

Table 2. Optimal Conditions for an Efficient RCM of 14<smiles>C=CCOCc1cccc(-c2ccnc(Nc3ccc(OCCN4CCCC4)c(COCC=C)c3)n2)c1</smiles>

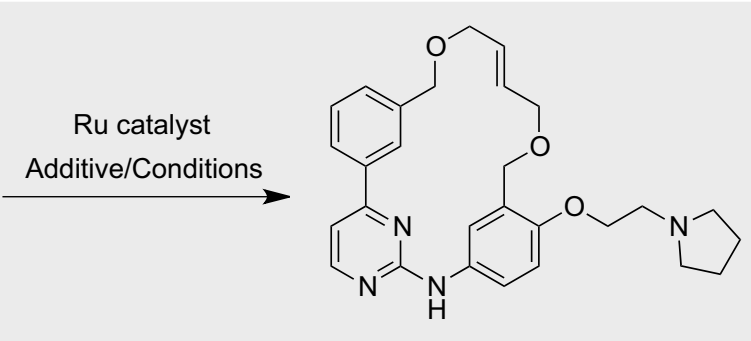

Entry Catalyst

1 Grubbs $1^{\text {st }}$ generation

mol \% Additive/Time trans: $^{\mathrm{a} i s^{\mathrm{b}}}$ yield, $\%^{c}$

2 Grubbs $2^{\text {nd }}$ generation

$25 \quad 36 \mathrm{~h}$ $n d$

$25 \quad 36 \mathrm{~h}$

nd

3 Grubbs $1^{\text {st }}$ generation

25

$\mathrm{HCl}, 36 \mathrm{~h}$

nd

35

4 Grubbs $2^{\text {nd }}$ generation

10

$\mathrm{HCl}, 3 \mathrm{~h}$

$85: 15$

10

TFA, $3 \mathrm{~h}$

$85: 15$

60

5 Hoveyda-Grubbs $2^{\text {nd }}$ generation

6 Zhan-1B

10

TFA, $3 \mathrm{~h}$

$85: 15$

67

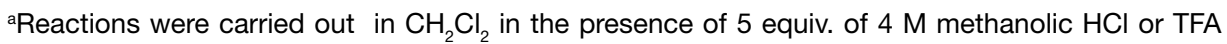
at reflux conditions. ' Determined by HPLC on crude sample. Isolated combined yields of cis and trans. nd, not determined. 
RCM in small molecule synthetic drugs and this will spur growth of development of small molecule macrocycles.

Received: January 29, 2015

[1] E. I. Graziani, Nat. Prod. Rep. 2009, 26, 602.

[2] E. M. Driggers, S. P. Hale, J. Lee, N. K. Terret, Nat. Rev. Drug Disc. 2008, 7, 608.

[3] C. A. Lipinski, F. Lombardo, B. W. Dominy, P. J. Feeney, Adv. Drug Del. Rev. 1997, 23, 3.

[4] a) A. Malorye, Nat. Biotech. 2005, 23, 639; b) S. M. Wilhelm, L. Adnane, P. Newell, A. Villanueva, J. M. Llovet, M. Lynch, Mol. Cancer Ther. 2008, 7, 3129.

[5] a) M. Malumbres, M. Barbacid, Nat. Rev. 2009, 9, 153; b) A. Tefferi, Cancer J. 2007, 13, 366; c) P. D. Kottaridis, R. E. Gale, D. C. Linch, Leuk Lymphoma. 2003, 44, 905; d) O. L. Roberts, K. Holmes, J. Müller, D. A. Cross, M. J. Cross, Biochem. Soc. Trans. 2009, 37, 1254; e) M. Malumbres, P. Pevarello, M. Barbacid, J. R. Bischoff, Trends in Pharmacol. Sci. 2008, 29,
16; f) S. Lapenna, A. Giordano, Nat. Rev. Drug Discov. 2009, 8, 547

[6] A. D. William, A. C. Lee, K. C. Goh, S. Blanchard, A. Poulsen, E. L. Teo, H. Nagaraj, C. P. Lee, H. Wang, M. Williams, E. T. Sun, C. Hu, R. Jayaraman, M. K. Pasha, K. Ethirajulu, J. M. Wood, B. W. Dymock, J. Med. Chem. 2012, $55,169$.

[7] a) A. Suzuki, Pure Appl. Chem. 1991, 63, 419; b) N. Miyaura, A. Suzuki, Chem. Rev. 1995, 95 2457.

[8] a) E. W. Baxter, A. B. Reitz. Org. Reactions 2002, 1, 59; b) A. F. Abdel-Magid, K. G Carson, B. D. Harris, C. A. Maryanoff, R. D. Shah, J. Org. Chem. 1996, 61, 3849.

[9] F. D. Bellamy, K. Ou, Tetrahedron Lett. 1984 $25,839$.

[10] S. Joshi, G. C. Maikap, S. Titirmare, A. Chaudhari, M. K. Gurjar, Org. Proc. Res. Dev. 2010, 14, 657 .

[11] T. W. Green, P. G. M. Wuts, 'Protective Groups Organic Synthesis', Wiley Interscience, New York, 1999.

[12] M. E. Jung, M. A. Lyster, J. Org. Chem. 1977, 42,3761 .
[13] E. E. Dueno, F. Chu, S.-I. K, K. W. Jung. Tetrahedron Lett. 1999, 40, 1843.

[14] a) S. Kim, W. Hwang, I. S. Lim, S. H. Kim, S. Lee, B. M. Kim, Tetrahedron Lett. 2010, 51, 709; b) A. Deiters, S. F. Martin, Chem. Rev. 2004, 104, 2199.

[15] A. D. William, A. C. Lee, S. Blanchard, A. Poulsen, E. L. Teo, H. Nagaraj, E. Tan, D. Chen, M. Williams, E. T. Sun, K. C. Goh, W. C. Ong, S. K. Goh, S. Hart, R. Jayaraman, M. K. Pasha, K. Ethirajulu, J. M. Wood, B. W. Dymock, J. Med. Chem. 2011, 54, 4638.

[16] A. Poulsen, A. D. William, B. W. Dymock, in 'Designed macrocyclic kinase inhibitors', in 'Macrocycles in drug discovery', Ed. J. Levin, Royal Society of Chemistry, London, 2014, p 141.

[17] a) For an update on clinical trials with SB1518 see http://clinicaltrials.gov; b) SB1518 codenamed Pacritinib has been sold to CTI BioPharma Corp.

[18] a) For an update on clinical trials with SB1317 see http://clinicaltrials.gov; b) SB1317 is licensed to Tragara Pharmaceuticals Inc. and entered the clinic as TG02 in mid-2010. 